\title{
A new concept of translational research in surgery
}

\section{Novo conceito de pesquisa translacional em cirurgia}

\section{Eiji Kobayashi $^{1}$, Edna Frasson de Souza Montero ${ }^{2}$}

1. M.D., Ph.D., Professor and Director; Centers for Molecular Medicine and Experimental Medicine, Jichi Medical School, Tochigi - Japan.

2. M.D., Ph.D., Afilliated Professor of the Operative Technique and Experimental Surgery, Escola Paulista de Medicina - Federal University of São Paulo, São Paulo - Brazil.

Translational research (TR) plays an important role for the clinical application of novel therapeutic strategies developed through experiments in basic sciences. TR allows being at the forefront of a real and relevant improvement in the management of some diseases. Surgical innovations or new operative techniques must be investigated and elaborated at the TR center, which has the potential for medical training and research development by young investigators involved in cutting edge, relevant science. A new concept of TR on surgery includes various fields of technique and science. Practical researches based on high level surgical technique, physiology, immunology, pharmacology, molecular biology, tissue engineering and ethics, are required and must be applied to improve continuously treatments for patients suffering from severe illnesses.

Development of experimental microsurgery opened a wide variety of worldwide researches and displayed excellent utility in the studies of surgery. Microsurgical technique is the basis of surgical experimental models, mainly in the transplant area. Microsurgical skills to many medical doctors who are postgraduate fellows from the standpoint of TR definitely contributed to clinical success.

Here, we would like to introduce this new concept of TR in surgery and emphasize that experimental microsurgery is a key part of TR. 